\title{
Analysis of Learning Curve in Robot-Assisted Radical Prostatectomy Performed by a Surgeon
}

\author{
Roman I. Slusarenco ${ }^{1},{ }^{1}$ Konstantin V. Mikheev, ${ }^{2}$ Artem O. Prostomolotov, ${ }^{1}$ \\ Roman B. Sukhanov, ${ }^{1}$ and Evgeny A. Bezrukov ${ }^{1}$ \\ ${ }^{1}$ Institute for Urology and Reproductive Health, Moscow, Russia \\ ${ }^{2}$ International School "Medicine of the Future", FGAOU VO I.M. Sechenov First Moscow State Medical University, \\ Moscow, Russia \\ Correspondence should be addressed to Roman I. Slusarenco; slusarenco.roman@gmail.com
}

Received 28 November 2019; Revised 16 March 2020; Accepted 4 May 2020; Published 26 May 2020

Academic Editor: Matthew Rutman

Copyright (C) 2020 Roman I. Slusarenco et al. This is an open access article distributed under the Creative Commons Attribution License, which permits unrestricted use, distribution, and reproduction in any medium, provided the original work is properly cited.

\begin{abstract}
This study aimed to report the learning curve in robot-assisted radical prostatectomy (RARP) performed by one surgeon who is experienced in laparoscopic prostatectomies. The records of 145 RARP cases performed between 2015 and 2017 were evaluated retrospectively. Patients were divided into three groups: group 1 comprised the first 49 cases, group 2 comprised 50-88 cases, and the rest of the cases were assigned to group 3. Continence was defined as the necessity to use at least one pad during a day. Additionally, erectile function recovery was defined as having erection sufficient for sexual intercourse regardless of using a phosphodiesterase type 5 inhibitor. Continence and erectile function recovery were assessed during interviews at 3,6 , and 12 months after surgery. First, all procedures were successfully performed without conversions or blood transfusions. The median follow-up period was 22 months. Moreover, the median skin-to-skin operative time (OT) was 220 minutes. The median blood loss was $150 \mathrm{ml}$, and the mean hospital stay was $8.9 \pm 3.87$ days. The median prostate volume was $36 \mathrm{~cm}^{3}$. The overall positive surgical margin rate was $13.1 \%$. Overall, $38(26.2 \%)$ postoperative complications were observed, and $17.9 \%$ of them were graded as minor. Anastomotic leakage decreased significantly from group 1 to group 3 ( $26.5 \%$ and $7 \%$, respectively). The continence recovery $(0-1$ pad) rates were $60.6 \%, 75.7 \%$, and $84.9 \%$ at 3,6 , and 12 months after surgery, respectively. Subsequently, the erectile function recovery rates were $50.9 \%$ and $65.4 \%$ at 6 and 12 months after surgery, respectively. In conclusion, there are several types of learning curves for RARP. First, the shallowest learning curve was observed for the OT. Regarding the analysis of "advanced learning curve," demonstrating the improvement of OT and blood loss is considered insufficient. Therefore, additional oncological and functional results that require a longer period of investigation are required.
\end{abstract}

\section{Introduction}

Prostate cancer is the second most common type of cancer and is the fifth leading cause of oncological death in men worldwide [1]. Prostatectomy is the gold standard treatment option for patients with localized disease [2]. Previously, this procedure was performed with a retropubic open approach [3]. The main drawbacks of this approach are as follows: long hospitalization, necessity of prescribing additional pain medication, and significant blood loss. Today, mini-invasive methods, such as laparoscopic radical prostatectomy (LRP) and robot-assisted radical prostatectomy (RARP), are becoming significantly more popular compared with the retropubic open approach. In particular, RARP has replaced retropubic radical prostatectomy (RRP) in Europe and the USA, which has been the gold standard surgical treatment of the localized and locally advanced prostate cancer [2]. Clearly, RARP has become the main standard treatment of prostate cancer. Recently, RARP has also demonstrated better outcomes than RRP and LRP. Although RARP has several advantages, adequate equipment and sufficient training programs are still required in this treatment method. Thus, this technique is rarely used in 
developing countries considering that it lacks financial support [4].

A short learning curve is one of the main advantages of the RARP, which makes it an interesting option for junior doctors. Certainly, surgeons who do not have significant experience in laparoscopic surgery achieve promising results. According to a recent study, doctors perform RARP more quickly compared with laparoscopic techniques [5]. Additionally, decreased intraoperative blood loss and reduced number of complications are observed after performing a total of 25-40 RARPs [6, 7]. Nevertheless, a significant clinical experience is still required to achieve adequate functional and oncological results in terms of negative surgical margins when performing RARP [8]. There are two types of learning curves, which can be used for RARP's assessment $[9,10]$. The "basic learning curve" includes 25-50 cases, after which the operative time (OT) decreases to 200-240 minutes [9]. In case of the "advanced learning curve," 100-300 cases are required to achieve stable erectile function and continence recovery [9]. There are several factors that affect the speed of surgical technique mastery including the following: initial surgical skills, type of the learning program, and experience in performing laparoscopic surgeries $[11,12]$. This study aimed to identify the pace of mastering RARP by a surgeon with significant clinical experience in performing LRP using the structured "advanced learning curve" method.

\section{Materials and Methods}

We studied 145 patients who had undergone radical robotic prostatectomy. It is worth mentioning that only one surgeon who is experienced in laparoscopic surgery had been performing RARP between 2015 and 2017. The data were collected retrospectively. All patients were divided into three groups according to the surgery date: group 1 comprised the first 49 cases, group 2 comprised 50-88 cases, and the rest of the cases were assigned to group 3 .

All patients underwent standard transperitoneal RARP. Pelvic lymph node dissection (PLND) was performed in case of possible lymph node involvement according to the Briganti nomogram [13]. Moreover, a nerve-sparing technique was performed when prostate cancer was localized according to the D'Amico classification. The postoperative general prostate-specific antigen (PSA) level was measured at 3, 6, 9, and 12 months after surgery. According to the recommendations, biochemical recurrence was considered provided that the general PSA level was higher than $0.2 \mathrm{ng} /$ $\mathrm{ml}$ [14]. Positive surgical margin (PSM) was defined as a tumor observed at the inked margin. Patients experiencing the extension of the tumor through the prostatic capsule were considered to experience extracapsular extension (pT3).

We considered our patients continent if they used a maximum of 1 pad per day. Continence was evaluated at 3, 6, and 12 months after surgery. Erectile function was evaluated at 6 and 12 months after surgery using the International Index of Erectile Function-5 (IIEF-5) score. Erectile function recovery was defined as the ability to achieve a sufficient erection for sexual intercourse regardless of using a phosphodiesterase type 5 (PDE 5) inhibitor. The initial results included OT (in minutes), positive surgical margins, blood loss volume, duration of urinary bladder catheterization, and continence and sexual function's recovery. Statistical analysis was performed using the International Business Machines Corporation Statistical for the Social Sciences Statistics version 23. $p<0.05$ was considered statistically significant.

\section{Results}

There were no statistically significant differences between the three groups in terms of age, body mass index, IIEF-5 total score, PSA level, prostate volume, Gleason score, clinical stage, D'Amico oncological risk, and possibility of lymph node invasion according to the Briganti nomogram (Table 1).

The median follow-up periods for groups 1,2 , and 3 were 24,22 , and 20 months, respectively $(p<0.001)$. The median age of the patients was $62.18 \pm 6.76$ years. The mean PSA level was $9.24 \pm 6.86 \mathrm{ng} / \mathrm{ml}$. The median OT (defined as the time from creating the first incision to creating the final skin suture, including the time of docking and undocking) was 220 (150-280) minutes. The OT decreased significantly from group 1 to group $3(p=0.0001)$ (Figure 1$)$.

Simultaneously, none of the patients required conversion. The median blood loss was $150(100-250) \mathrm{ml}$. As the surgeon gained experience, blood loss decreased: group 1, $250(150-400) \mathrm{ml}$; group 2, $150(100-250) \mathrm{ml}$; and group 3, $100(100-175) \mathrm{ml}(p=0.0002)$. None of the patients required blood transfusion (Figure 2).

Overall, 38 (26.2\%) postoperative complications were observed using the Clavien-Dindo classification, and 26 of them $(17.9 \%)$ were graded as minor (Clavien I/II) (Table 2).

Clavien IV/V complications were not observed. The incidence rates of anastomotic leakage that required prolonged catheter duration were $26.5 \%, 23.1 \%$, and $7.0 \%$ in groups 1,2 , and 3 , respectively $(p<0.02)$. Six major urine extravasations, which required unilateral or bilateral ureteral mono-J stent placement, were observed in the early postoperative period. Six patients required cystoscopy and repeat catheter placement due to major urine extravasation after catheter removal (Table 3 ).

Extended PLND was performed in only 38 patients (26\%). A total of nine patients from group 3 underwent pelvic lymphadenectomy up to the level of the abdominal aorta bifurcation (Table 4).

According to the histological investigation results, the Gleason total score and pT stage were equal in all the three groups $(p>0.05)$. Extracapsular invasion (pT3) and seminal vesicle invasion (pT3b) were observed in $13.79 \%$ and $7.6 \%$ of patients, respectively. The overall PSM rate was $13.1 \%$, corresponding to $8.2 \%$ in pT2 and $19.7 \%$ in pT3. A comparison of the pT2 $(p=0.065), \operatorname{pT} 3(p=0.162)$, and the overall groups $(p=0.07)$ showed no statistically significant difference (Table 5).

We considered our patients continent if they used a maximum of 1 pad per day. Continence was defined as the 
TABle 1: Preoperative clinical characteristics of the patients.

\begin{tabular}{|c|c|c|c|c|c|}
\hline Characteristics & Median value & Group $1(1-49)$ & Group $2(50-88)$ & Group 3 (89-145) & $p$ value \\
\hline \multicolumn{6}{|l|}{ Age (years) } \\
\hline Mean \pm SD & $62.18 \pm 6.76$ & $61.29 \pm 6.73$ & $63.56 \pm 6.75$ & $62.00 \pm 6.76$ & \multirow{2}{*}{0.42} \\
\hline Median (IQR) & $62(57.5-67)$ & $62(57-67)$ & $63(60-68)$ & $62(57-66.5)$ & \\
\hline \multicolumn{6}{|l|}{ BMI } \\
\hline Mean \pm SD & $27.24 \pm 3.85$ & $26.76 \pm 3.91$ & $27.28 \pm 4.71$ & $27.64 \pm 3.11$ & \multirow{2}{*}{0.52} \\
\hline Median (IQR) & $27.0(25.0-28.7)$ & $27.1(24.6-28.5)$ & $26.5(24.6-29.0)$ & $27.0(25.6-29.0)$ & \\
\hline \multicolumn{6}{|l|}{ IIEF-5, $n(\%)$} \\
\hline $21-25$ points & $60(53.1)$ & $17(53.1)$ & $13(46.4)$ & $30(56.6)$ & \multirow{4}{*}{0.35} \\
\hline $16-20$ points & $24(21.2)$ & $8(25.0)$ & $4(14.3)$ & $12(22.6)$ & \\
\hline $11-15$ points & $10(8.8)$ & $4(12.5)$ & $2(7.1)$ & $4(7.5)$ & \\
\hline $0-10$ points & $19(16.8)$ & $3(9.4)$ & $9(32.1)$ & $7(13.2)$ & \\
\hline \multicolumn{6}{|l|}{ PSA (ng/ml) } \\
\hline Mean \pm SD & $9.24 \pm 6.86$ & $8.48 \pm 5.97$ & $8.71 \pm 5.65$ & $10.25 \pm 8.19$ & \multirow{2}{*}{0.553} \\
\hline Median (IQR) & $7.47(5.5-9.8)$ & $7.47(5.6-9.1)$ & $6.97(5.3-9.9)$ & $8.00(5.7-10.6)$ & \\
\hline \multicolumn{6}{|c|}{ Prostate volume $\left(\mathrm{cm}^{3}\right)$} \\
\hline Mean \pm SD & $39.84 \pm 17.14$ & $38.53 \pm 17.57$ & $41.74 \pm 20.87$ & $39.58 \pm 13.82$ & \multirow{2}{*}{0.55} \\
\hline Median (IQR) & $36.0(29.0-47.5)$ & $33.0(26.5-49.5)$ & $34.00(29-50)$ & $40(30.00-45.5)$ & \\
\hline \multicolumn{6}{|c|}{ Clinical stage, $n(\%)$} \\
\hline $\mathrm{cT} 1$ & $90(62.1)$ & $34(69.4)$ & $23(59.0)$ & $33(57.9)$ & \multirow{3}{*}{0.8} \\
\hline cT2 & $40(27.6)$ & $11(22.4)$ & $13(33.3)$ & $16(28.1)$ & \\
\hline cT3 & $15(10.3)$ & $4(8.2)$ & $3(7.7)$ & $8(14.0)$ & \\
\hline \multicolumn{6}{|c|}{ Biopsy Gleason score, $n(\%)$} \\
\hline$\leq 6$ & $89(61.4)$ & $32(65.3)$ & $28(71.8)$ & $29(50.9)$ & \multirow{3}{*}{0.08} \\
\hline$=7$ & $48(33.1)$ & $17(34.7)$ & $10(25.6)$ & $21(36.8)$ & \\
\hline$\geq 8$ & $8(5.5)$ & $0(0)$ & $1(2.6)$ & $7(12.3)$ & \\
\hline \multicolumn{6}{|c|}{ D’Amico risk, $n(\%)$} \\
\hline Low & $78(53.8)$ & $28(57.1)$ & $29(74.4)$ & $21(36.8)$ & \multirow{3}{*}{0.128} \\
\hline Median & $38(26.2)$ & $14(28.6)$ & $5(12.8)$ & $19(33.3)$ & \\
\hline High & $29(20)$ & $7(14.3)$ & $5(12.8)$ & $17(29.8)$ & \\
\hline \multicolumn{6}{|c|}{ Briganti lymph node invasion, $n(\%)$} \\
\hline$<5 \%$ & $92(63.4)$ & $34(69.4)$ & $26(66.7)$ & $32(56.1)$ & \multirow{2}{*}{0.33} \\
\hline$\geq 5 \%$ & $53(36.6)$ & $15(30.6)$ & $13(33.3)$ & $25(43.9)$ & \\
\hline
\end{tabular}

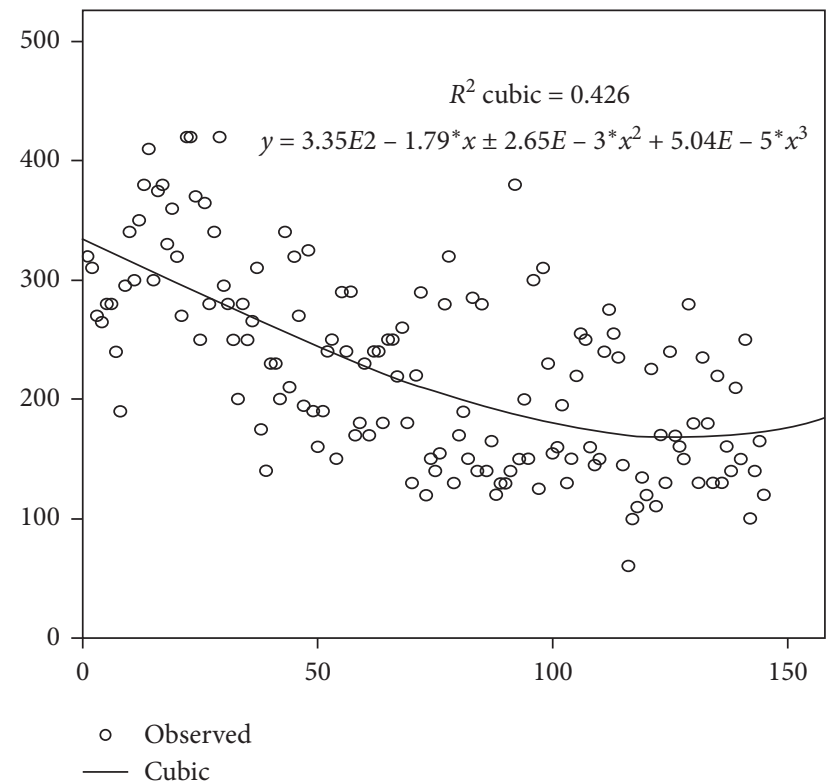

FIGURE 1: Learning curve for the operative time.

necessity to use one pad per day. Thus, at 3, 6, and 12 months after surgery, the overall continence rates were $60.6 \%, 75.7 \%$, and $84.9 \%$, respectively. In comparison with urinary

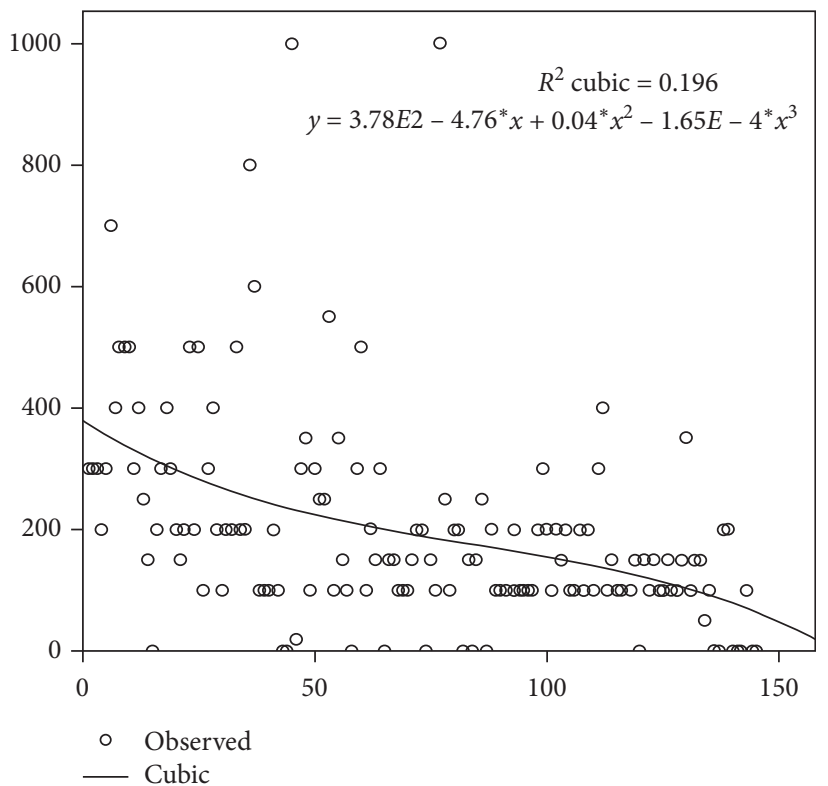

FIgURE 2: Learning curve for the blood loss.

incontinence among the observed groups, at 3 months after surgery, the rates were $64.5 \%, 66.7 \%$, and $53.5 \%$, respectively $(p=0.146)$, and there was no statistically significant 
TABLE 2: Intraoperative data.

\begin{tabular}{|c|c|c|c|c|c|}
\hline Characteristic & Median (total) & Group $1(1-49)$ & Group 2 (50-88) & Group $3(89-145)$ & $p$ \\
\hline \multicolumn{6}{|c|}{ Operative time (OT) (min) } \\
\hline Mean \pm SD & $224.17 \pm 80.87$ & $293.57 \pm 68.81$ & $204.23 \pm 57.48$ & $178.16 \pm 62.22$ & \multirow{2}{*}{0.0001} \\
\hline Median (IQR) & $220(150-280)$ & $295(250-340)$ & $190(150-250)$ & $160(130-227.50)$ & \\
\hline \multicolumn{6}{|l|}{ Console time (min) } \\
\hline Mean \pm SD & $120.45 \pm 56.40$ & $163.06 \pm 58.26$ & $107.44 \pm 38.16$ & $92.72 \pm 42.35$ & \multirow{2}{*}{0.0002} \\
\hline Median (IQR) & $100(80-155)$ & $160(115-210)$ & $100(80-130)$ & $80(70-110)$ & \\
\hline \multicolumn{6}{|l|}{ Blood loss (mL) } \\
\hline Mean \pm SD & $199.10 \pm 175.09$ & $290.20 \pm 206.8$ & $189.74 \pm 182.1$ & $127.19 \pm 84.02$ & \multirow{2}{*}{0.0002} \\
\hline Median (IQR) & $150(100-250)$ & $250(150-400)$ & $150(100-250)$ & $100(100-175)$ & \\
\hline \multicolumn{6}{|l|}{ Hospital stay (days) } \\
\hline Median (IQR) & $11(8.5-14)$ & $12(9-16)$ & $11(7-15)$ & $10(8-12.5)$ & 0.007 \\
\hline \multicolumn{6}{|c|}{ Abdominal drains, $n(\%)$} \\
\hline Placed & $69(47.6)$ & $39(79.6)^{*}$ & $21(53.8)$ & $9(15.8)^{*}$ & \multirow{2}{*}{0.0001} \\
\hline Not placed & $76(52.4)$ & $10(20.4)$ & $18(46.2)$ & $48(84.2)$ & \\
\hline \multicolumn{6}{|l|}{ Complications, $n(\%)$} \\
\hline Clavien grade I/II & $26(17.9)$ & $13(26.5)^{*}$ & $9(23.1)$ & $4(7.0)^{*}$ & 0.02 \\
\hline Clavien grade III & $12(8.3)$ & $8(16.3)^{*}$ & $2(5.1)$ & $2(3.5)^{*}$ & 0.116 \\
\hline
\end{tabular}

${ }^{*}$ Statistically significant difference.

TABLe 3: Complications stratified by the Clavien-Dindo classification system.

\begin{tabular}{lccccc}
\hline Grade & Complications & $\begin{array}{c}\text { Group 1 } \\
(1-49)\end{array}$ & $\begin{array}{c}\text { Group 2 } \\
(50-88)\end{array}$ & $\begin{array}{c}\text { Group 3 } \\
(89-145)\end{array}$ & Management \\
\hline I/II & Anastomosis leakage & 13 & 9 & 4 & 2 \\
\hline IIIA & $\begin{array}{c}\text { Major urine extravasation during } \\
\text { catheterization }\end{array}$ & 3 & 1 & 1 & 0 \\
\hline IIIA & $\begin{array}{c}\text { Major urine extravasation after catheter } \\
\text { removal }\end{array}$ & 5 & $\begin{array}{c}\text { Cystoscopy and catheter } \\
\text { placement }\end{array}$ \\
\hline
\end{tabular}

TABLE 4: Operative technique.

\begin{tabular}{|c|c|c|c|c|c|}
\hline Characteristic & Total & Group $1(1-49)$ & Group $2(50-88)$ & Group $3(89-145)$ & $p$ \\
\hline \multicolumn{6}{|l|}{ Nerve sparing, $n(\%)$} \\
\hline Nonnerve sparing & $56(38.6)$ & $14(8.6)$ & $17(43.6)$ & $25(43.9)$ & \multirow{4}{*}{0.035} \\
\hline Bilateral & $73(50.3)$ & $27(55.1)$ & $15(38.5)$ & $31(54.4)$ & \\
\hline Unilateral & $14(9.7)$ & $7(14.3)^{*}$ & $7(17.9)$ & $0(0.0)^{*}$ & \\
\hline Partial bilateral & $2(1.4)$ & $1(2.0)$ & $0(0.0)$ & $1(1.8)$ & \\
\hline \multicolumn{6}{|l|}{ Prostatectomy technique, $n(\%)$} \\
\hline Intrafascial & $72(49.7)$ & $25(51)$ & $15(38.5)$ & $32(56.1)$ & \multirow{4}{*}{0.023} \\
\hline Interfascial & $8(5.5)$ & $6(12.2)^{*}$ & $2(5.1)$ & $0(0)^{*}$ & \\
\hline Extrafascial & $59(40.7)$ & $15(30.6)$ & $19(48.7)$ & $25(43.9)$ & \\
\hline Combined technique & $6(4.1)$ & $3(6.1)$ & $3(7.7)^{*}$ & $0(0)^{*}$ & \\
\hline \multicolumn{6}{|c|}{ Prostate venous plexus (PVP) suture ligation, $n(\%)$} \\
\hline No suture ligation & $21(14.5)$ & $3(6.1)^{*}$ & $10(25.6)^{*}$ & $8(14)$ & \multirow{3}{*}{0.034} \\
\hline Suture ligation before transection & $83(57.2)$ & $32(65.3)^{*}$ & $15(38.5)^{*}$ & $36(63.2)$ & \\
\hline Suture ligation after transection & $41(28.3)$ & $14(28.6)$ & $14(35.9)$ & $13(22.8)$ & \\
\hline \multicolumn{6}{|l|}{ Anterior reconstruction } \\
\hline Not performed & $66(45.5)$ & $20(40.8)$ & $24(61.5)^{*}$ & $22(38.6)^{*}$ & \multirow{2}{*}{0.045} \\
\hline Performed & $79(54.5)$ & $29(59.2)$ & $15(38.5)^{*}$ & $35(61.4)^{*}$ & \\
\hline \multicolumn{6}{|l|}{ Posterior reconstruction, $n(\%)$} \\
\hline Performed & $26(17.9)$ & $12(24.5)$ & $6(15.4)$ & $8(14.0)$ & \multirow{2}{*}{0.33} \\
\hline Not performed & $119(82.1)$ & $37(75.5)$ & $33(84.6)$ & $49(86.0)$ & \\
\hline \multicolumn{6}{|c|}{ Pelvic lymph node dissection (PLND), $n(\%)$} \\
\hline Not performed & $107(73.8)$ & $36(73.5)$ & $32(82.1)$ & $39(68.4)$ & \multirow{3}{*}{0.003} \\
\hline Up to the ureter level & $29(20.0)$ & $13(26.5)$ & $7(17.9)$ & $9(15.8)$ & \\
\hline Up to the aorta bifurcation level & $9(6.2)$ & $0(0)^{*}$ & $0(0)$ & $9(15.8)^{*}$ & \\
\hline
\end{tabular}

* Statistically significant difference. 
TABLE 5: Histological results.

\begin{tabular}{|c|c|c|c|c|c|}
\hline Characteristics & Total & Group 1 (1-49) & Group $2(50-88)$ & Group 3 (89-145) & $p$ \\
\hline \multicolumn{6}{|l|}{ Pathological stage (pT), $n(\%)$} \\
\hline pT2 & $125(86.21)$ & $41(83.67)$ & $34(87.18)$ & $50(87.72)$ & 0.51 \\
\hline \multicolumn{6}{|l|}{ Postoperative Gleason score, $n(\%)$} \\
\hline$\leq 6$ & $65(44.8)$ & $25(51.0)$ & $18(46.2)$ & $22(38.6)$ & \multirow{3}{*}{0.2} \\
\hline 7 & $71(49.0)$ & $24(49.0)$ & $17(43.6)$ & $30(52.6)$ & \\
\hline$\geq 8$ & $9(6.2)$ & $0(0.0)$ & $4(10.3)$ & $5(8.8)$ & \\
\hline \multicolumn{6}{|l|}{ Invasion, $n(\%)$} \\
\hline No invasion (pT2) & $102(70.3)$ & $36(73.5)$ & $32(82.1)$ & $34(59.6)$ & \multirow{4}{*}{0.097} \\
\hline Capsular infiltration (pT2) & $23(15.9)$ & $5(10.2)$ & $3(7.7)$ & $16(28.1)$ & \\
\hline Extracapsular invasion (pT3) & $20(13.79)$ & $8(16.33)$ & $5(12.82)$ & $7(12.28)$ & \\
\hline Seminal vesicle (pT3b) & $11(7.6)$ & $3(6.1)$ & $3(7.7)$ & $5(8.8)$ & \\
\hline \multicolumn{6}{|l|}{ Surgical margin status, $n(\%)$} \\
\hline Positive & $19(13.10)$ & $3(6.12)$ & $9(23.08)$ & $6(10.53)$ & \multirow{2}{*}{0.07} \\
\hline Negative & $126(86.9)$ & $46(93.88)$ & $30(76.92)$ & $51(89.47)$ & \\
\hline
\end{tabular}

difference between the three groups. At 6 months after surgery, continence was completely restored in $77.4 \%$, $86.7 \%$, and $66.7 \%$ of patients, respectively $(p=0.034)$. At 12 months after surgery, $83.0 \%, 89.6 \%$, and $82.1 \%$ of patients were continent in groups 1, 2, and 3, respectively $(p=0.237)$, with no statistically significant difference between the three groups. Erectile function was considered to be restored if erection was sufficient for sexual intercourse regardless of using a (PDE 5) inhibitor. Hence, erectile function recovery was achieved in 50.9\% (IIEF-5 score, 13.9) and $65.4 \%$ (IIEF-5 score 15.3) of patients at 6 and 12 months after surgery, respectively $(p=0.176)$. There were no statistically significant differences in the observed groups.

\section{Discussion}

RARP has become the most common surgical procedure that is used in the treatment of localized prostate cancer. Surgeons prefer RARP over other surgical methods because of its mini-invasive characteristics and short learning curve. Patel et al. found that only 25 surgeries have to be performed to master RARP [7].

Nevertheless, each surgeon has his/her own learning curve and needs to perform an individual number of surgeries to achieve desirable results.

The main intraoperative index is OT, which is changing as long as the surgeon masters the RARP technique. Long operations are possibly associated with technical difficulties and lack of surgical skills [15]. In our study, the median (skin to skin) OT (interquartile range (IQR)) was 220 (150-280) minutes, which decreased after the 88-th case. According to Doumerc et al., if a surgeon had experience in performing open prostatectomies, 110 cases would be required to achieve the OT of 180 minutes [16]. Our results are consistent with the results of Haglind et al.'s study, which demonstrated that the median OT in the group of RARP was 236 minutes.

The median blood loss was 150 (100-250) ml. Evidently, it decreased after completing a hundred of cases by $100 \mathrm{ml}$ in group 3 (median level, IQR). According to the statistical data, blood loss rates during RARP vary from $142 \mathrm{ml}$ to $230 \mathrm{ml}$ [17], which is considered another advantage of RARP over open radical prostatectomy. According to TobiasMachado et al., the median blood loss during the first 60 robot-assisted radical prostatectomies was $245.5 \mathrm{ml}$, as the surgeon had already performed 200 laparoscopic radical prostatectomies [18]. In our investigation, the median hospital stay was $8.9 \pm 3.87$ days although Rocco et al. mentioned the 3-day hospital stay [19]. Certainly, hospital stay is longer in Russia than that in the recent study considering the differences between the two healthcare systems.

The overall complication rate was $26.2 \%$. Particularly, the complication rates were $17.9 \%$ and $8.3 \%$ for Clavien I/II and Clavien IIIA complications, respectively. According to Rocco et al., the overall anastomotic leakage rate was $24 \%$, with the anastomoses diagnosed by the postoperative retrograde cystogram. These results could be compared with our data (median rate of 17.9\%) [19]. Moreover, the anastomotic leakage rate was evidently lower as the surgeon was gaining experience than that of group $1(26.5 \%$ and $7 \%$, respectively).

Finally, according to Hruza et al., the complication rates were $21.7 \%$ for Clavien I/II and $11.5 \%$ for Clavien III [20].

Certainly, the main goal of surgical treatment is to achieve the optimal oncological results. Hence, the PSM was the most important rate. According to the systematic review by Yossepowitch et al., the overall PSM rate in different studies varies from $6.5 \%$ to $32 \%$ [21]. In our investigation, the overall PSM rate was $13.1 \%$, and the PSM rates in pT2 and pT3 were $8.2 \%$ and $19.7 \%$, respectively. These results are consistent with the abovementioned results. Interestingly, the PSM rate did not change alongside the learning curve evidently, suggesting that a surgeon should continue to master one's skills after performing 150 surgeries. Some investigators believe that the PSM rate did not change alongside the learning curve because the tipping point might have not been achieved yet [22].

We also believe that the data obtained from Patel et al. should be paid careful attention because they showed that PSM could significantly change after performing 1500 surgeries (e.g., $12.2 \%$ for $1-300$ cases, $6.6 \%$ for $301-600$ cases, $13.6 \%$ for $601-900$ cases, $11 \%$ for $901-1.200$ cases, and $1.8 \%$ for $1201-1500$ cases) [23]. 
Biochemical recurrence was observed in $16.5 \%$ of patients at the end of the study period.

Ploussard et al. [24] determined that the overall continence rates (unnecessary use of pads after RARP) were $50.3 \%, 72 \%$, and $83.6 \%$ at 3, 6, and 12 months after surgery, respectively. This result is consistent with the result of our present study (continence rates of $60.6 \%, 75.7 \%$, and $84.9 \%$ at 3, 6, and 12 months after surgery, respectively).

Another important life quality rate is erectile function. Erectile function recovery rates at 6 and 12 months after surgery were $50.9 \%$ (IIEF-5 score, 13.9) and 65.4\% (IIEF-5 score, 15.3), respectively. In one study (Ploussard et al.), $42 \%$ and $57.7 \%$ of patients demonstrated adequate erectile function at 6 and 12 months after surgery, respectively [24]. Kim et al. reported that erectile function was restored in 33\% and $57.1 \%$ of patients at 3 and 6 months, respectively, in the large RARP group $(n=528)$ [25].

Our investigation has a number of limitations. First, this was a nonrandomized and retrospective study. Second, a short period of supervision was observed in this study. The results were assessed throughout the 12-month period after surgery. In RARP, the skills of a surgeon should be developed constantly. Third, small sample sizes were observed in the three groups, decreasing the sample value. Finally, continence and erectile function recovery rates were evaluated through patient interviews without the use of questionnaires.

During the whole learning curve, we observed the considerable improvement of the following rates: OT, blood loss volume, hospital stay duration, anastomotic leak frequency after surgery (according to the cystographic results), and frequency of abdominal cavity draining. Simultaneously, a longer period of investigation and manual practicing are required to evaluate PSM and BCR and urine continence and sexual function recovery.

\section{Conclusions}

In conclusion, the results of our study have provided evidence that surgeons with previous surgical experience require more than 80 cases to achieve an OT of 180 minutes. The median blood loss, which was approximately $150 \mathrm{ml}$, was achieved approximately after performing 50 surgeries. Moreover, the PSM had not significantly changed after performing 145 surgeries. Regarding urinary incontinence and erectile function, surgeons started performing simple surgeries and eventually managed to perform nerve-sparing techniques with anterior and posterior reconstructions for better clinical outcomes.

\section{Data Availability}

The data used to support the findings of this study are available from the corresponding author upon request.

\section{Conflicts of Interest}

The authors declare that there are no conflicts of interest regarding the publication of this paper.

\section{References}

[1] J. Ferlay, I. Soerjomataram, R. Dikshit et al., "Cancer incidence and mortality worldwide: sources, methods and major patterns in GLOBOCAN 2012," International Journal of Cancer, vol. 136, no. 5, pp. E359-E386, 2015.

[2] N. Mottet, J. Bellmunt, M. Bolla et al., "EAU-ESTRO-SIOG guidelines on prostate cancer. Part 1: screening, diagnosis, and local treatment with curative intent," European Urology, vol. 71, no. 4, pp. 618-629, 2017.

[3] P. C. Walsh, A. W. Partin, and J. I. Epstein, "Cancer control and quality of life following anatomical radical retropubic prostatectomy: results at 10 years," Journal of Urology, vol. 152, no. 5 Part 2, pp. 1831-1836, 1994.

[4] C. Bolenz, S. J. Freedland, B. K. Hollenbeck et al., "Costs of radical prostatectomy for prostate cancer: a systematic review," European Urology, vol. 65, no. 2, pp. 316-324, 2014.

[5] T. E. Ahlering, D. Skarecky, D. Lee, and R. V. Clayman, "Successful transfer of open surgical skills to a laparoscopic environment using a robotic interface: initial experience with laparoscopic radical prostatectomy," Journal of Urology, vol. 170, no. 5, pp. 1738-1741, 2003.

[6] J. A. Smith Jr., "Robotically assisted laparoscopic prostatectomy: an assessment of its contemporary role in the surgical management of localized prostate cancer," The American Journal of Surgery, vol. 188, no. 4, pp. 63-67, 2004.

[7] V. R. Patel, A. S. Tully, R. Holmes, and J. Lindsay, "Robotic radical prostatectomy in the community setting-the learning curve and beyond: initial 200 cases," Journal of Urology, vol. 174, no. 1, pp. 269-272, 2005.

[8] Y. H. Ko, J. H. Ban, S. H. Kang et al., "Does robot-assisted laparoscopic radical prostatectomy enable to obtain adequate oncological and functional outcomes during the learning curve? From the Korean experience," Asian Journal of Andrology, vol. 11, no. 2, pp. 167-175, 2009.

[9] H. J. Lavery, D. B. Samadi, R. Thaly et al., "The advanced learning curve in robotic prostatectomy: a multi-institutional survey," Journal of Robotic Surgery, vol. 3, no. 3, pp. 165-169, 2009.

[10] T. Hashimoto, K. Yoshioka, T. Gondo et al., "Learning curve and perioperative outcomes of robot-assisted radical prostatectomy in 200 initial Japanese cases by a single surgeon," Journal of Endourology, vol. 27, no. 10, pp. 1218-1223, 2013.

[11] A. Volpe, K. Ahmed, P. Dasgupta et al., "Pilot validation study of the European association of urology robotic training curriculum," European Urology, vol. 68, no. 2, pp. 292-299, 2015.

[12] C. Lovegrove, G. Novara, A. Mottrie et al., "Structured and modular training pathway for robot-assisted radical prostatectomy (RARP): validation of the RARP assessment score and learning curve assessment," European Urology, vol. 69, no. 3, pp. 526-535, 2016.

[13] A. Briganti, A. Larcher, F. Abdollah et al., "Updated nomogram predicting lymph node invasion in patients with prostate cancer undergoing extended pelvic lymph node dissection: the essential importance of percentage of positive cores," European Urology, vol. 61, no. 3, pp. 480-487, 2012.

[14] N. Mottet, EAU-ESTRO-ESUR-SIOG Guidelines on Prostate Cancer 2018 in European Association of Urology Guidelines, European Association of Urology Guidelines Office, Arnhem, Netherlands, 2018.

[15] A. J. Vickers, C. J. Savage, M. Hruza et al., "The surgical learning curve for laparoscopic radical prostatectomy: a 
retrospective cohort study," The Lancet Oncology, vol. 10, no. 5, pp. 475-480, 2009.

[16] N. Doumerc, C. Yuen, R. Savdie et al., "Should experienced open prostatic surgeons convert to robotic surgery? The real learning curve for one surgeon over 3 years," BJU International, vol. 106, no. 3, pp. 378-384, 2010.

[17] Q.-D. Trinh, J. Sammon, M. Sun et al., "Perioperative outcomes of robot-assisted radical prostatectomy compared with open radical prostatectomy: results from the nationwide inpatient sample," European Urology, vol. 61, no. 4, pp. 679-685, 2012.

[18] M. Tobias-Machado, A. I. Mitre, M. Rubinstein, E. F. d. Costa, and A. K. Hidaka, "Roboticssisted radical prostatectomylearning curve for experienced laparoscopic surgeons: does itreally exist," International Brazilian Journal of Urology, vol. 42, no. 1, pp. 83-89, 2016.

[19] B. Rocco, D.-V. Matei, S. Melegari et al., "Robotic vs open prostatectomy in a laparoscopically naive centre: a matchedpair analysis," BJU International, vol. 104, no. 7, pp. 991-995, 2009.

[20] M. Hruza, H. O. Weiß, G. Pini et al., "Complications in 2200 consecutive laparoscopic radical prostatectomies: standardised evaluation and analysis of learning curves," European Urology, vol. 58, no. 5, pp. 733-741, 2010.

[21] O. Yossepowitch, A. Briganti, J. A. Eastham et al., "Positive surgical margins after radical prostatectomy: a systematic review and contemporary update," European Urology, vol. 65, no. 2, pp. 303-313, 2014.

[22] Y. M. Hong, D. E. Sutherland, B. Linder, and J. D. Engel, "Learning curve" may not be enough: assessing the oncological experience curve for robotic radical prostatectomy," Journal of Endourology, vol. 24, no. 3, pp. 473-477, 2010.

[23] V. R. Patel, K. J. Palmer, G. Coughlin, and S. Samavedi, "Robot-assisted laparoscopic radical prostatectomy: perioperative outcomes of 1500 cases," Journal of Endourology, vol. 22, no. 10, pp. 2299-2306, 2008.

[24] G. Ploussard, A. de la Taille, M. Moulin et al., "Comparisons of the perioperative, functional, and oncologic outcomes after robot-assisted versus pure extraperitoneal laparoscopic radical prostatectomy," European Urology, vol. 65, no. 3, pp. 610-619, 2014.

[25] S. C. Kim, C. Song, W. Kim et al., "Factors determining functional outcomes after radical prostatectomy: robotassisted versus retropubic," European Urology, vol. 60, no. 3, pp. 413-419, 2011. 